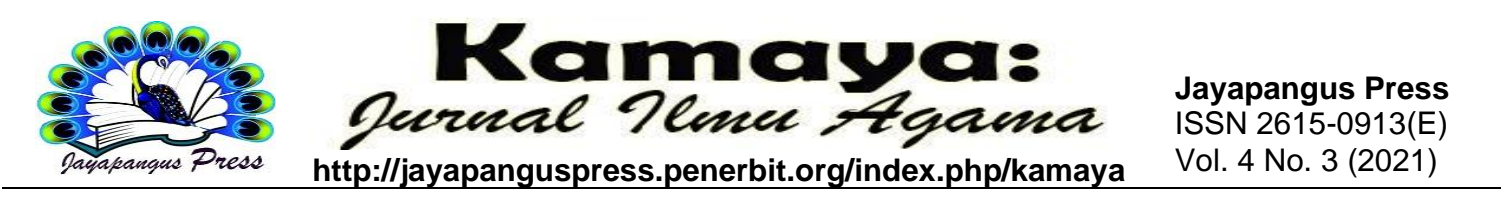

\title{
Bentuk-Bentuk Sesapa Dalam Pelaksanaan Ritual Saṃskāra Di Desa Pedawa Buleleng Bali
}

\author{
I Nyoman Suka Ardiyasa', Putu Maria Ratih Anggraini2 \\ ${ }^{12}$ STAH N Mpu Kuturan Singaraja \\ 15suka.ardiyasa@gmail.com, ${ }^{2}$ mariaratihanggraini@gmail.com
}

\begin{tabular}{l}
\hline Keywords: \\
\hline Sesapa Form, \\
Sampskāra, \\
Pedawa Village \\
\hline
\end{tabular}

\begin{abstract}
The use of Sesapa in carrying out religious rituals in Pedawa Village is the main thing, even though Hindus generally use Mantra as their language of worship. In Bali Aga Village, especially in Pedawa Village, the use of Sesapa or Balinese Dialect Pedawa has become the main language that cannot be replaced until now. This study questions the use of Sesapa in the implementation of religious rituals carried out in the Bali Aga Village. The method used in this research is descriptive qualitative. Data was collected by using interview and direct observation techniques. The results of this study indicate that the implementation cycle of Samskāra in Pedawa Village consists of (1) kayeh di cangkupe, (2) pungsed kepus (kepus puser), (3) nampi, (4) nampangang abulan pitung dina, (3) tiga bulanan, ( 4) ngotonin, (5) nyambutin, (6) nyrimpen, (7) pawiwahan, (8) metatah, (9) death ceremony and (10) ngangkid. While the form of greeting used by the people of Bali Aga Village is in the form of Balinese dialect Pedawa which is shown to the Gods, to the Ancestors, and to the Bhutas.
\end{abstract}

Kata Kunci:

Bentuk Sesapa, Saṃskāra Desa Pedawa

\begin{abstract}
Abstrak
Penggunaan Sesapa dalam pelaksanaan ritual keagamaan di Desa Pedawa menjadi hal yang utama, padahal Hindu secara umum menggunakan bahasa Mantra sebagai bahasa pemujaannya. Di Desa Bali Aga khususnya di Desa Pedawa penggunaan Sesapa atau Bahasa Bali Dialek Pedawa menjadi bahasa utama yang tidak bisa tergantikan hingga kini. Penelitian ini menyoal penggunaan Sesapa dalam pelaksanaan Ritual keagamaan yang dilaksanakan di Desa Bali Aga. Metode yang digunakan dalam penelitian ini adalah deskriptif kualitatif. Pengumpulan data dilakukan dengan teknik wawancara dan observasi langsung. Hasil penelitian ini menunjukan bahwa siklus pelaksanaan Saṃskāra di Desa Pedawa terdiri dari (1) kayeh di cangkupe, (2) kepus pungsed (kepus puser), (3) nampi, (4) nanggapang abulan pitung dina, (3) tiga bulanan, (4) ngotonin, (5) nyambutin, (6) nyerimpen, (7) pawiwahan, (8) metatah, (9) upacara kematian dan (10)
\end{abstract}


ngangkid. Sedangkan bentuk sesapa yang digunakan oleh masyarakat Desa Bali Aga berupa Bahasa Bali Dialek Pedawa yang ditunjukan kepada Para Dewa, kepada para Leluhur, dan kepada Para Bhuta.

\section{Pendahuluan}

Sesapa atau lebih dikenal dengan dengan sesontengan bagi masyarakat Bali merupakan sesuatu yang tidak asing, terutama bagi mereka yang menganut agama Hindu Bali. Hampir dalam setiap prosesi persembahyangan penggunaa bahasa lokal selalu digunakan dalam pemujaan terutama dalam hal mengucapkan permohonan kepada Ida Sang Hyang Widhi Wasa. Sesapa adalah ucapan penganteb dengan kata-kata sehari-hari yang dilakukan oleh masyarakat Hindu dalam persembahyangan untuk menyampaikan keinginan. Ada beberapa bahasa yang digunakan untuk menyampaikan keinginan itu, misalnya dengan bahasa Bali, bahasa Kawi atau disebut dengan Sesapa atau Sesontengan. Jika dalam pengucapan permohonannya menggunakan bahasa Sansekerta maka disebut sebagai mantra. Begitupula dalam pengucapannya jika memakai bahasa Sanskerta maka diucapkan dengan cara menyayikannya (seronca atau sruti), sedangkan jika doa dengan bahasa Kawi maka ucapannya dengan menggunakan palawakia, dan jika berdoa dengan menggunakan bahasa Bali maka ucapannya seperti berkomunikasi biasa dengan orang yang lebih tinggi atau dikenal dengan bahasa nyinggihang dengan menggunakan bahasa Bali yang tergolong ASI (Alus Singgih). Melihat pengertian tersebut sesungguhnya Sesapa bukanlah mantra, jika mantra menggunakan bahasa Sansekerta sebagai bahasa pengantarnya sedangkan Sesapa menggunakan bahasa lokal sebagai bahasanya. Mantra diartikan sebagai Bahasa yang benar yang merupakan ucapan suci yang digunakan dalam pemujaan (Danielou dalam Titib $2003: 473)$.

Keberagaman doa-doa yang diucapakan dalam berbagai siklus ritual masyarakat memiliki variasi yang sangat kompleks baik dari sistem religinya, sistem teologinya termasuk penggunaan bahasanya. Menurut Martha (2018 :7) ada 16 siklus sistem penyucian diri manusia yang dilakukan menurut tradisi India yaitu Garbhadana Samskāra (baru dinyatakan hamil s/d 3 bulan), Punsavan (kehamilan 4-6 bulan), Simantoyan (kehamilan 7-9 bulan), Jatakarma (anak baru lahir), Niskama (anak sudah bisa diajak ke luar rumah), Namakarma (memberikan nama sampai 11 hari), Mundan (menggunduli anak), Karnadeva (menindik anak khususnya putri), Annaprasan (anak 
baru pertama kali diberikan makan), Upanayana (anak-anak mulai memasuki sekolah), Vedarambha (anak-anak baru diberikan pendidikan veda), Samavartana (anak telah menyelesaikan pendidikannya), Grahasta (memasuki rumah tangga), Vanaparasta (meninggalkan kehidupan duniawi), Bhiksuka (memasuki dunia spiritual) sampai Antyesthi Samskāra (kematian/ngaben). Dalam tradisi Hindu Bali ada 13 siklus yang wajib dilakukan diantaranya magedong-gedongan (saat kadungan berumur 5 atau 7 bulan kalender), kelahiran bayi, kepus puser, ngelepas hawon (bayi genap berumur 12 hari), upacara Tutug Kambuhan (bayi berumur 42 hari), upacara tiga bulanan (bayi berumur 3 bulan), upacara satu oton (bayi berumur 6 bulan), upacara tumbuh gigi, upacara tanggal gigi, upacara raja sewala, mapandes, pawiwahan, dan ngaben.

Secara umum masyarakat Hindu Bali meyakini 13 siklus tersebut harus dilalui dalam kehidupannya. Saṃskāra adalah ritual peralihan, juga persiapan, pemurnian, penyempurnaan dari kondisi masa lalu seseorang ke kondisi masa depan seseorang (Carl Olson, 2007 : 93). Samskkāra memiliki berbagai makna yang didorong oleh konteks, yang secara luas merujuk pada penyatuan untuk mencapai yang sempurna, membuat sempurna, suatu bentuk pengakuan khidmat dan bersiap-siap, terlibat dalam karya-karya dan mengakui pemurnian tubuh dengan pembersihan atau pikiran dengan pendidikan atau objek melalui suatu proses seperti halnya memoles permata atau memurnikan logam (Monier Williams, 1999 : 224). Dengan demikian siklus tersebut sesungguhnya merupakan sebuah proses yang harus dilalui oleh umat Hindu dalam menjalani kehiduapan di dunia ini dari baru lahir hingga menuju kematian dengan tujuan agar terjadi penyucian dan pemurnian diri manusia.

Pada kepercayaan masyarakat Bali Aga, keseluruhan rangkaian Saṃskāra tersebut tidak seutuhnya dilalui bahkan sebagian ada yang dilakukan seperti tradisi umat Hindu Bali ada pada umumnya, ada juga yang sama sekali tidak mengikuti tradisi yang ada pada umumnya. Misalnya saja upacara Ngangkid yang dilakukan oleh masyarakat Desa Pedawa. Ngangkid merupakan upacara kematian yang bertujuan sebagai korban suci kepada arwah dengan jalan mengangkat roh dari Sungai Pengangkidan untuk selanjutnya diwujudkan (kaadegang) pada Kunduh. Kunduh adalah perwujudan roh (semacam sekah) (Sukrata, 1995 : 56). Tentu upacara Ngangkid ini tidak sama dengan Ngaben seperti upacara yang dilakukan umat Hindu Bali pada umumnya, namun esensinya sama yaitu penghormatan kepada leluhur. Begitu pula pada siklus-siklus upacara yang dilakukan oleh masyarakat, tidak semuanya dilakukan. 
Dari Fenomena tersebut bahwa peranan Sesapa bagi masyarakat Desa Pedawa sangatlah penting terutama dalam pelaksanaan Samskāra sehingga dalam keseluruhan pelaksanaan Balian Desa selalu menggunakan Sesapa. Tulisan ini akan membahas tentang bentuk-bentuk sesapa yang digunakan dalam pelaksanaan Saṃskāra di Desa Pedawa.

\section{Metode}

Penelitian ini menggunakan metode deskriptif kualitatif. Menurut Moleong (2013 : 16), penelitan kualitatif bermaksud untuk memahami fenomena yang dialami sendiri oleh subjek penelitian secara holistik lalu dideskripsikan dalam bentuk paparan kebahasaan yang dapat berupa kata-kata atau teks tulis. penelitian lapangan (field research) yang bertujuan melihat dan mengamati tentang doa-doa (Sesapa) yang diucapkan dalam rangkaian upacara yang dilakukan oleh masyarakat Desa Pedawa dari lahir hingga kematiannya (Saṃskāra). Ada tiga langkah yang dilakukan dalam pengumpulan data penelitian ini, diantaranya dengan cara observasi sekaligus perekaman pelaksanaan ritual yang dilakukan pada Desa Bali Aga, selanjutnya adalah proses wawancara dengan Balian Desa dan tokoh-tokoh yang dianggap memahami Sesapa di Desa Bali Aga. Setelah itu barulah melakukan studi dokumen, khususnya dokumen yang terkait dengan Sesapa. Dari keseluruh proses tersebut terlebih dahulu dilakukan transkrip dari ucapan Sesapa oleh yang diungkapkan oleh Balian Desa. Transkrip inilah dijadikan data primer dalam menganalisis bentuk dan makna dari Sesapa yang digunakan oleh masyarakat Bali Aga dalam pelaksanaan ritual.

\section{Hasil Dan Pembahasan}

\section{Pelaksanaan Saṃskāra di Desa Pedawa}

Pelaksanaan Samskāra bagi umat Hindu di Bali merupakan sebuah kewajiban yang harus dilakukan sebab bagi manusia yang lahir di dunia wajib terus melakukan upaya membersihkan diri dari segala kotoran atau mala yang ada didalam dirinya dari baru lahir hingga menjelang kematiannya. Dalam konteks lebih luas pelaksanaan Saṃskāra diartikan sebagai sebuah penyatuan untuk mencapai yang sempurna, membuat sempurna, suatu bentuk pengakuan khidmat dan bersiap-siap, terlibat dalam karya-karya dan mengakui pemurnian tubuh dengan pembersihan atau pikiran dengan pendidikan atau objek melalui suatu proses seperti halnya memoles permata atau 
memurnikan logam. Dengan demikian siklus tersebut sesungguhnya merupakan sebuah proses yang harus dilalui oleh umat Hindu dalam menjalani kehidupan di dunia ini dari baru lahir hingga menuju kematian dengan tujuan agar terjadi penyucian dan pemurnian diri manusia.

Merujuk pendapatnya Martha (2018:7) ada 16 siklus sistem penyucian diri manusia yang dilakukan menurut tradisi India yaitu Garbhadana Samskāra (baru dinyatakan hamil s/d 3 bulan), Punsavan (kehamilan 4-6 bulan), Simantoyan (kehamilan 7-9 bulan), Jatakarma (anak baru lahir), Niskama (anak sudah bisa diajak ke luar rumah), Namakarma (memberikan nama sampai 11 hari), Mundan (menggunduli anak), Karnadeva (menindik anak khususnya putri), Annaprasan (anak baru pertama kali diberikan makan), Upanayana (anak-anak mulai memasuki sekolah), Vedarambha (anak-anak baru diberikan pendidikan veda), Samavartana (anak telah menyelesaikan pendidikannya), Grahasta (memasuki rumah tangga), Vanaparasta (meninggalkan kehidupan duniawi), Bhiksuka (memasuki dunia spiritual) sampai Antyesthi Saṃskāra (kematian/ngaben). Dalam tradisi Hindu Bali ada 13 siklus yang wajib dilakukan diantaranya magedong-gedongan (saat kadungan berumur 5 atau 7 bulan kalender), kelahiran bayi, kepus puser, ngelepas hawon (bayi genap berumur 12 hari), upacara Tutug Kambuhan (bayi berumur 42 hari), upacara tiga bulanan (bayi berumur 3 bulan), upacara satu oton (bayi berumur 6 bulan), upacara tumbuh gigi, upacara tanggal gigi, upacara raja sewala, mapandes, pawiwahan, dan ngaben.

Secara umum masyarakat Hindu Bali meyakini 13 siklus tersebut harus dilalui dalam kehidupannya. Saṃskāra adalah ritual peralihan, juga persiapan, pemurnian, penyempurnaan dari kondisi masa lalu seseorang ke kondisi masa depan seseorang (Carl Olson, 2007 : 93). Samskāra memiliki berbagai makna yang didorong oleh konteks, yang secara luas merujuk pada penyatuan untuk mencapai yang sempurna, membuat sempurna, suatu bentuk pengakuan khidmat dan bersiap-siap, terlibat dalam karya-karya dan mengakui pemurnian tubuh dengan pembersihan atau pikiran dengan pendidikan atau objek melalui suatu proses seperti halnya memoles permata atau memurnikan logam (Monier Williams, 1999 : 224). Dengan demikian siklus tersebut sesungguhnya merupakan sebuah proses yang harus dilalui oleh umat Hindu dalam menjalani kehiduapan di dunia ini dari baru lahir hingga menuju kematian dengan tujuan agar terjadi penyucian dan pemurnian diri manusia. 
Selanjutnya pelaksanaan Saṃskāra atau Siklus penyucian manusia dari baru lahir hingga meninggal di Desa Pedawa terlihat berbeda dengan pelaksanaan upacara manusa yadnya pada umumnya, namun sejatinya makna yang terkandung dibalik segala prosesi ritual dan upakara yang digunakan memiliki arti dan makna yang tidak jauh berbeda. Pelaksanan siklus Samskāra di Desa Pedawa dilakukan sesuai dengan tradisi keberagamaan di Desa Pedawa yang diterima secara turun-temurun dengan ritus dan perlengkapan yadnya yang khas Bali Kuna. Pelaksanaan ritualnya cenderung menggunakan konsep-konsep desa dresta /acara atau kebiasaan-kebiasaan adat yang dilakukan sejak jaman dahulu.

Menurut penuturan tokoh Adat Pedawa yang juga sebagai Balian Desa (Pan Karpani) menyebut ada sejumlah ritual siklus Saṃskāra atau penyucian manusia di Desa Pedawa dari lahir sampai menghembuskan nafas terakhirnya diantaranya : (1) Kayeh di Cangkupe, (2) Kepus Pungsed (Kepus Puser), (3) Nampi, (4) Nanggapang Abulan Pitung Dina, (3) Tiga Bulanan, (4) Ngotonin, (5) Nyambutin, (6) Nyerimpen, (7) Pawiwahan, (8) Metatah, (9) Upacara Kematian dan (10) Ngangkid. Dari keseluruhan proses yang dilakukan tersebut semunya dilaksanakan oleh Balian Desa dan Jro Tapini (Tukang Banten).

\section{Siklus Samskāara Di Desa Pedawa}

Kayeh di Cangkupé (Melukat di Campuhan) merupakan tradisi mandi (kayeh) di tempat sungai yang mengalami perpaduan air 2 (dua) sungai atau lebih menjadi satu aliran (cangkup) dapat dikatakan sebagai prosesi awal dari rangkaian prosesi Saṃskāra di Desa Pedawa. Upacara dilakukan ketika seseorang sedang mengandung. Upacara ini sesungguhnya tidak dilakukan oleh semua ibu yang hamil, namun mereka mengininkan keselamatan bagi bayinya, terlebih-lebih bagi mereka yang mengetahui terjadi keadaan kurang baik kondisi bayinya dalam kandungan seperti posisi bayinya ngandang dan keluhan-keluhan bayi masih dalam kandungan. Namun sekarang ini pelaksanaan nyangling atau mandi di cangkup ini sudah mulai dilakukan bagi masyarakat Pedawa yang hamil dengan kisaran umur 2-5 bulan kandungan. Berdasarkan hasil wawancara dengan Balian Desa (Pan Karpani) disebutkan sebagai berikut :

Yen carah dini, anak liunan ane campah gati nang anak beling, ada meneh ara mekudiang-kudiang, ara taen nang nyangkup, kula yen saihang nang ipidan, jani ba liunan masih anae ani apik, men nak apanga seger pyanakne di tengah, 
nah yen ani apik, uba mejalan nang dua nganteg lima bulan uba biasane ya nyangkup, binane anak akicak gatine saranane ani, tah misi canang daksina baas pipis, canang meraka, tipat bekel, tipat gong nang caru atuwunan Terjemahannya :

Jika seperti yang berjalan di Pedawa, banyak sekali yang tidak serius memperhatikan orang hamil, sampai-sampai ada tanpa upacara apapun, tidak pernah mandi di campuhan, tetapi jika dibandingkan dengan masa lalu, sekarang sudah banyak juga masyarakat yang telaten, dengan harapan sehatnya anaknya dalam kandungan. dan apabila ada yang telaten, umur 2 sampai 5 bulan kandungan sudah biasanya mandi ke campuhan. Dan mengenai upacaranya sangat simpel sekali, hanya mempersembahkan canang daksina baas pipis, canang meraka, tipat bekel, tipat gong dan caru satu pasang. (wawancara 12 April 2021).

Jika dilihat pelaksanaan upacara yang serupa pada masyarakat Bali umumnya pelaksanaan Kayeh di Cangkupé (Melukat di Campuhan) hampir mirip pelaksanaanya dengan upacara magedong-gedongan. merupakan upacara adat Hindu Bali dalam rangkaian upacara adat kehamilan. Bertemunya Kama Jaya (Sperma) dan Kama Ratih (Ovum) menciptakan wujud manusia dalam bentuk bayi. Upacara megedong-gedongan adalah upacara pertama yang ditujukan kepada bayi dalam kandungan sang ibu ketika berusia 5 bulan Bali (kurang lebih 6 bulan dalam kalender masehi). Pada usia tersebut, bayi telah dianggap memiliki wujud yang lebih sempurna dan telah berwujud manusia. Upacara megedong-gedongan memiliki tujuan untuk menyucikan atau membersihkan bayi dalam kandungan. Masyarakat Hindu Bali percaya dengan dilakukannya upacara ini, bayi dalam kandungan tidak mudah gugur (abortus). Upacara ini juga bertujuan untuk menguatkan sang anak dan sang ibu agar persalinan berjalan lancar. Disamping itu sang bayi diharapkan setelah lahir dapat memiliki budi yang luhur, menjadi seorang anak yang berguna bagi keluarga, masyarakat, dan negara, serta selalu diberikan keselamatan dalam hidup.

Pada saat kepus puser hanya dilakukan upacara mepengerapuhan yaitu dengan memohon air suci kepada orang pintar dengan harapan anak yang sudah kepus pusernya bisa hidup sehat, dan segala kotorannya hilang. Upacara Nampi adalah upacara yang dilakukan setelah bayi lahir sebelas hari, dilakukanlah upacara nampi. yaitu dengan mempersembahkan banten penampi dengan nunas tirta kepada orang pintar atau Balian 
Desa. Nanggapang Abulan pitung Dina dilaksanakan pada bayi berumur satu bulan tujuh hari. Sejenis "ngaluang/nyapatin" di Bali tengah dan Bali selatan, upacara ini dilakukan dengan nunasang kepada orang pintar di Desa Pedawa dan menanyakan tentang siapa yang menjelma atau reinkarnasi itu. Ciri-ciri dari pelaksanaan nanggapang ini adalah menggunakan tempat tirta dari beruk dan menggunakan pengetisan dengan tiga pucuk pohon yaitu pucuk dap-dap tis, pucuk tabah dan menireng. Banten yang digunakan pada prosesi ini yaitu banten penanggapan.

Upacara tiga bulanan dilaksanakan pada saat prosesi ini banten yang digunakan adalah banten penanggapan hampir sama dengan banten nanggapang abulan pitung dina, namun yang membedakan dengan prosesi upacara yang pertama yaitu pada saat upacara tiga bulanan ini ciri-ciri pelaksanaannya yaitu tempat tirta nya berupa jun pirian dengan sarana pengetisan pitung pemujaan atau tujuh pucuk pohon yaitu : kayu tulak, kayu sisih, andong bang, sudamala, lalang, bungan jepun, dadap tis. Banten nya sama dengan yang pertama namun tempat tirta nya yang berbeda yaitu dengan menggunakan payuk kedas dengan penirtan 7 (tujuh) pemujan yaitu kayu tulak, kayu sisih, andong bang, sudamala, lalang, bungan jepun, dadap tis.

Pelaksanaan upacara nyambutain tidak ditentukan dengan pasti, dilakukan ketika tersedianya dana tetapi sebelum anak menek kelih, namun beberapa keluarga juga melakukan walaupun umurnya sudah dewasa. Kata nyambutin hampir memiliki makna sama dengan nelu bulanin, walaupaun kita tahu nelubulanin dilakukan saat bayi berumur tiga bulan dan nyambutin saat bayi setelah umur tiga bulanan bahkan sebelum tanggal gigi. Berikut wawancara dengan salah satu tukang banten di Pedawa: “̈̈en anae dini keneha nyambutin kadong te ba tua anak dadi, kewala yen ngidaang nu kicak, bagusan kunya, kewala anak pipise masih mekada" (Wawancara dengan Wayan Sukrata, 12 Mei 2021)

Upacara Nyrimpen ini dilakukan sebanyak tiga kali pada setiap anak. yaitu dilakukan pada hari suci Galungan dengan sarana yang bersamaan dengan Banten Galungan. Upacara yang pertama disebut Nyerimpen Sibakan, kedua disebut dengan Nyerimpen Sibakan dan ketiga disebut dengan Nyerimpen Nampah Ukudan. Upacara ini juga bisa dilakukan hanya sekali oleh keluarga yang kurang mampu, yaitu Nyerimpen Sibakan saja. Nganten (Pawiwahan) upacara ini dilakukan dalam dua versi. Pertama dilakukan dengan istilahnya pragat di kayehan, yang artinya ada ritual yang dilakukan di tempat permandian umum yang berfungsi sebagai penghilang segala kotoran pada 
mempelai, dan kedua dilakukan dengan istilah mebasang yaitu upacara dengan banten lengkap ke merajan dan ayaban di perumahan. (wawancara dengan I Suwida, 13 juni 2016). Metatah/Mesangih merupakan acara Potong Gigi bagi anak yang akan menek bajang. Mesangih baru lumrah dilakukan setelah tahun 60-an. Dan sekarang dilakukan dengan cara massal oleh masyarakat Pedawa. Hal unik didalam upacara metatah ini adalah adanya ritual ngendekang apabila warga desa menyelenggarakan upacara mesangih, hal ini sesuai dengan awig-awig palet 4 pawos 48 indik manusa yadnya, yang sampai saat ini dilakukan oleh masyarakat Desa Pedawa.

Upacara Ngangkid merupakan Upacara Ngaben yang dilakukan dengan tradisi Desa Pedawa. Meskipun memiliki tujuan yang sama, yaitu sebagai upacara kematian, tetapi sebenarnya upacara Ngangkid dan upacara Ngaben itu berbeda. Upacara Ngangkid merupakan suatu pelaksanaan korban suci kepada arwah dengan jalan mengangkat roh dari Sungai Pangangkidan, untuk selanjutnya diwujudkan (kaadegang) pada Kunduh. Kunduh adalah perwujudan roh (semacam Sekah). Tujuan pelaksanaan upacara ini adalah agar arwah atau roh mencapai alam para dewa atau Surga dan sebagai pembayaran utang sentana kepada leluhur. Berbeda dengan upacara Ngaben, dalam upacara Ngangkid, pembakaran mayat dilakukan dengan api abstrak berupa tirta pabersihan terhadap kekotoran atau dosa-dosa arwah. Tirta itulah yang berasal dari Tukad Pangangkidan.

Menurut kepercayaan masyarakat Desa Pedawa, Tukad Pangangkidan dianggap sebagai tempat arwah menjalani hukuman. Selain itu, Tukad Pangangkidan diyakini merupakan tempat Bhatari Durga dalam wujud Yamadipati. Sedangkan tempat Ngababang Kunduh adalah pangutangan Lis. Pangutangan Lis dianggap sebagai pintu gerbang atau jalan menuju alam Surga. Di sini pula tempat Dewa Bagus Manik Ngleluer yang menerima dan mengantar roh ke Surga. Upacara Ngangkid dilaksanakan berpedoman dengan lalintihan dan selalu dilakukan setelah upacara Sabha (Odalan/Pujawali) di pura. Alasannya agar upacara Ngangkid tidak nyebelin Sabha. Apabila upacara Ngangkid dilaksanakan pada waktu Sabha, maka akan mengakibatkan roh tidak mendapat tempat di alam baka.

\section{Bentuk Sesapa dalam Proses Pelaksanaan Samıskāra}

Bentuk dari Sesapa dalam proses pelaksanaan Saṃkāra menggunkan dialek Bahasa Bali Aga Pedawa. Menurut orang Pedawa, bahasa atau dialek yang digunakan di 
desa-desa itu mempunyai banyak perbedaan dibandingkan dengan bahasa yang digunakan di Desa Pedawa walaupun lokasinya dekat. Kendati demikian mereka masih bisa berkomunikasi dengan penutur dari empat desa tersebut dengan memakai bahasa atau dialek masing-masing. Selain itu, juga dikatakan bahwa bahasa atau dialek yang dipakai di Desa Banyuseri sudah dipengaruhi dialek Bahasa Bali Aga. Masyarakat Desa Pedawa juga menyatakan bahwa mereka pernah bisa berkomunikasi dengan orang Bali Aga yang tinggal lebih jauh, seperti di Kintamani dan Tenganan, dengan memakai bahasanya masing-masing ada beberapa kesamaan berkaitan dengan istilah-istilah yang disampaikan oleh kedua orang tersebut. Dalam kaitannya dengan penelitian ini bahwa penggunan Bahasa Bali dialek Bali Aga digunakan sebagai bahasa utama oleh Balian Desa dalam muput (memimpin acara) rangkaian upacara Samskāra di Desa Pedawa. Secara umum bentuk Sesapa yang digunakan Balian Desa ada 3 (tiga) yaitu bentuk sesapa permohonan kepada para Dewa, bentuk sesapa permohonan kepada para Bhuta dan kepada Leluhur. Berikut adalah penjelasan terkait dengan bentuk-bentuk Sesapa yang digunakan oleh Balian Desa Pedawa dalam muput (memimpin acara) rangkaian upacara Samskāra.

\section{a. Bentuk Sesapa Kepada Para Dewa}

Bentuk Sesapa yang ditujukan kepada para Dewa berupa verba dan nonverba. Bentuk nonverba itu berupa perlengkapan banten sesuai dengan jenis upacara, sedangkan bentuk verbanya berupa ungkapan Sesapa dalam bentuk bahasa Bali Dialek Bali Aga yang sederhana. Bentuk verba Sesapa yang ada sangat bervariatif sesuai dengan setting, dan jenis upacara. Adapun pengucapannya sangat lembut. Salah satu bentuk verba yang dimaksud dilihat pada bentuk wacana berikut.

Ainggih naweg titiang nunas lugra ngerihin ring Ida Pengakan Prataksu sané patut ngélingang ngéncakang iriki ring wewidangan wewengkon inggian payalan anggén ipun pakubon panjak druwé lampon macecingak.

Terjemahannya

Baik ijinkan saya memohon ijin medahului kehadapan Ida Pengakan Prataksu yang sepatutnya memberi tahukan berkuasa disini di seluruh wilayah , sebagai sarana tempat tinggal hambamu semoga bisa melihat kami disini. (Wawancara Jro Balian Desa, 12 Mei 2021). 
Dari Sesapa yang diucapkan diatas terlihat jelas bahwa bahasa yang digunakan adalah Bahasa Bali Alus, sebab yang diajak bicara adalah perwujudan Tuhan dalam bentuk Ida Pengakan Prataksu yang diyakini oleh masyarakat Desa Pedawa sebagai Dewa yang dipuja dalam setiap pelaksanaan Yadnya. Dalam pengucapannya sangat lembut dan yang mengucapkan Sesapa memposisikan dirinya sebagai hambanya yang berada dibawah sehingga bahasa yang dipakai lebih dominan Bahasa Alus Singgih. Dalam ucapan Sesapa kepada para dewa, bentuk sapaan yang bervariasi digunakan, seperti kata Cokor Dewa/Cokor I Dewa, Ida Gede Kemulan Sakti/I Gede Sakti Kemulan. Jika melihat penggunaan kata Cokor I Dewa artinya mengucapkan Sesapa menganggap bahwa yang dipuja adalah ibarat raja yang dimohon oleh seorang bawahannya. Berikut adalah contoh penggunaan Sesapa yang menyebutkan Cokor I Dewa :

antuk teenan takilan pekembangang cracapan getah uyung rauhin tipat gong madaging panggul asapunika anggén ipun wantah nyanggra makerauh Ida Cokor I Dewa Gede Kemulan Sakti ring wit penyanding iriki wénten antuk Ida Bhatara Ida Bhatari teler kadi mangkin.

Terjemahannya

Oleh sebab itu maka sarana berupa takilan pekembangang cracapan getah uyung sampai dengan tipat gong yang berisi panggul sebagai sarana menymabut kedatangan Ida Cokor I Dewa Gede Kemulan Sakti yang merupakan sumber pembanding disini juga ada Ida Bhatari Ida Bhatari seperti sekarang ini. (Wawancara Jro Balian Desa, 12 Mei 2021)

Dari kutipan tersebut penggunaan kata Cokor I Dewa merupakan bentuk hormat kepada beliau I Dewa Gede Kemulan Sakti. Dalam konteks kebahasaan Cokor juga berati batis atau kaki, kata cokor juga sering digunakan pada penyapaan bangsa kesatria seperti Cokor I Ratu, Cokor I Dewa (kepada raja), ring ajeng Cokor I Ratu dihadapan paduka tuanku.

Disamping itu bentuk kata yang lain yang sering disebutkan jika memuja para dewa adalah penggunaan kata Titiang. Dalam sor singgih bahasa Bali penggunaan kata titian termasuk dalam kata Alus Singgih. Kata titiang artinya saya, jika dalam Alus Sor maka kata Titiang akan berubah menjadi tiang, bahkan yang lebih kasar lagi digunakan kata Ake, Kola Siga dll. Berikut adalah contoh Sesapa dengan menggunkan kata Titiang 
Ida Bhatara Ida Bhatari teler kadi mangkin mangda nénten kapitandruh titiang riantukan taler nguningang kadi mangda ledang rauh taler antuk mecantuk rai iring titiang Ida raka Rai Ida Hyang sané kasungsung panjak druwé ring Gunung Sari Pedawa antuk panjak druwené nunas amerta sari.

Terjemahannya

Ida Bhatara Ida Bhatari seperti sekarang ini supaya tidak kena permasalahan saya memberitahukan supaya maklum datang bertemu muka dan menjamu Ida raka Rai Ida Hyang yang dipuja seluruh masyarakat yang ada disini khsusnya di Gunung Sari pedawa sebagai tempat memohon kesejahteraan. (Wawancara Jro Balian Desa, 12 Mei 2021).

Jika seseorang membicarakan orang yang patut dimuliakan, maka seyogyanya harus menggunakan kata kata alus atau disebut sebagai bahasa singgih. Bahasa Singgih digunakan tidak hanya berhadapan dengan orang yang dimuliakan tetapi juga dipergunakan sewajarnya bagi semua orang yang patut dihormati terlebih-lebih dalam pemujaan kepada Ida Sang Hyang Widhi Wasa. Kata Titiang merupakan jenis kata Alus Singgih dimana kata alus singgih pada umumnya digunakan untuk menghormati sesorang yang patut dihormati. Dalam konteks Sesapa yang diucapakan oleh Balian Desa, kata Titiang merupakan wujud penghormatan kepada para Dewa yang dipuja dalam proses pelaksanaan Samskāra tersebut.

\section{b. Bentuk Sesapa Kepada Para Bhuta Kala}

Bhuta Kala sebutan yang diberikan pada sosok mahluk jahat dengan wujud wajah menyeramkan, galak dan muncul sebagai makhluk penggoda. Menghuni tempattempat yang angker, jurang dan pohon-pohon besar, demikian juga tempat yang tidak pernah dijamah atau bangunan yang telah lama ditinggalkan manusia adalah rumahnya. Banyak legenda mengisahkan bhuta kala yang dihubungkan dengan kehidupan manusia bahkan juga kehidupan para dewa. Beberapa dari legenda tersebut memberikan kisah terjadinya suatu tempat, nama suatu daerah dan ritual sebuah upacara sakral. Sebut saja salah satunya upacara potong gigi yang sumber ceritanya diambil dari kisah Bhatara Kala yang ingin bertemu kedua orang tuanya yaitu Bhatara Siwa dan Bhatara Uma Parwati. Kisah ini sangat melekat dikalangan masyarakat dan menjadi tradisi bahwa setiap orang melakukan upacara potong gigi semasa hidupnya, terlebih lagi bagi mereka yang ingin mendalami ajaran agama. Sorga pun tidak dapat dicapai bila orang yang mati 
belum pernah melakukan ritual potong gigi semasa hidupnya yang lebih akrab disebut sebagai Upacara Mepandes.

Kepercayaan kepada Bhuta juga dipercayai keberadaannya oleh Masyarakat Desa Pedawa, hal ini tercermin dalam pelaksanaan Samskāra pemujaan kepada Bhuta juga dilakukan baik dalam bentuk banten/segehan juga dalam Sesapanya juga diucapkan pemujaan kepada para Bhuta. Bentuk pemujaan kepada bhuta dapat dilihat dari Sesapaan yang diucapakan oleh Dane Balian Desa dalam melakukan proses nganteb upacara. Beberapa kalimat yang menunjukan ada pemujaan kepada Bhuta :

kadi mangkin iriki mangda lédang rauh para bhuta sinareng sami mangda prasida ngupasaksi ring pangrestitian antuk ring ibu pertiwi sané madué gumi iriki nyelang genahé puniki ring ibu pertiwi anggén ipun genah pakubon taler pagenah serahina wengi.

Terjemahannya

Seperti sekarang disini supaya bisa hadir para bhuta semuanya, agar bisa menyaksikan permohonan kepada ibu pertiwi yang mempunyai wilayah disini meminjam tempat disini kepad ibu pertiwi dipakai tempat tinggal dan tempat beraktifitas setiap hari dari pagi hingga malam. (wawanacara Dane Balian Desa 12 Mei 2021).

Dari petikan Sesapa tersebut bentuk pemujaan kepada bhuta masih tetap menggunakan bahasa Bali Alus, hal ini terlihat dari penggunaan kata-kata Alus Singgih seperti kata lédang rauh, iriki nyelang genahé puniki. Pemilihan kata tersebut masih menunjukan rasa hormat karena Bhuta masih dianggap diluar golongan manusia yang diyakini memiliki kekuatan lebih dari manusia, sehingga wajib di dilakukan penghormatan. Pemberian bentuk hormat yang diucapakan dalam Sesapa ditunjukan pada para dewa, butakala, dan roh leluhur karena ketiga tersebut dianggap sistem pengelompokan masyarakat, yang dianggap lebih tinggi daripada manusia. Oleh karena itu, penggunaan bahasa Alus Singgih terjadi lewat kosakata bidang agama dan kepercayaan khsususnya pelaksanaan Sesapa di Desa Pedawa.

c. Bentuk Sesapa Kepada Leluhur.

Pemujaan leluhur di Desa Pedawa telah berkembang sejak jaman megalitik hingga kini, ditunjukkan dengan tinggalan beragam yang memiliki fungsi penghormatan kepada leluhur. Hal ini dapat dilihat dari banyaknya temuam berupa ; sarkofagus, hiasan kedok muka, dan lain-lain. Sarkofagus adalah wadah kubur seseorang yang dipandang 
berjasa dalam masyarakat disertai dengan berbagai bekal kubur sebagai suatu bentuk penghormatan kepada arwah seseorang yang telah berjasa. Penghormatan dan perlakuan seperti itu dilakukan berdasarkan atas kepercayaan kepada arwah leluhur, yang dianggap memiliki kekuatan magis, dapat menentukan nasib keluarga dan masyarakat. Untuk menjaga ketentraman dan kesejahteraan masyarakat, maka selalu dijaga hubungan dengan dunia arwah melalui upacara pemakaman. (Sutaba, 1994:104-109).

Pemujaan leluhur di Desa Pedawa sejalan dengan perkembangan kebudayaan Hindu di Indonesia. Dalam perkembangannya mengalami proses akulturasi dan enkulturasi sesuai dengan lingkungan budaya Nusantara. Kepercayaan kepada gunung sebagai alam arwah, adalah relevan dengan unsur kebudayaan Hindu yang menganggap gunung, khususnya Gunung Mahameru sebagai alam dewata. Hal ini melahirkan konsep bahwa gunung selain dianggap sebagai alam arwah juga sebagai alam para dewa. Proses lebih lanjut melalui tingkatan upacara keagamaan tertentu roh suci leluhur dapat mencapai tempat yang sama dan dipuja bersama-sama dalam satu tempat pemujaan dengan dewa yang lazimnya disebut dengan istilah Atma siddha dewata. Tradisi pemujaan roh leluhur yang dinamakan Dewa Pitra, dilaksanakan pada tempat-tempat pemujaan, seperti sanggah atau merajan, pura dadya atau paibon, pura panti, dan pedharman (Linus, 1986: 205-206; Titib, 2003: 94).

Perpaduan dua unsur budaya dari masa yang berbeda, tampak pada kebudayaan fisik seperti pola dan tata ruang pemukiman.umumnya masyarakat Bali Aga khsususnya di Desa Pedawa memiliki rumah tinggal yang disebut tampul roras. Tampul roras adalah rumah bertiang 12 yang tergolong besar ini dirancang sedemikian rupa terbagi dalam beberapa ruangan. Ruang tersebut antara lain tumpang salu sebagai tempat pemujaan, ruang suci juga difungsikan sebagai tempat tidur bagi orang yang belum dewasa, ruang tidur, dapur disebut penggak pengamahan. Bangunan ini dapat dibandingkan dengan arsitektur tradisional Bali yang bernuansa Hindu di daerah dataran, mempunyai pola dasar yang sama, hanya letak bangunannya tidak dalam satu rumah, namun tertata dalam satu pekarangan. Letak bangunan antara yang satu dengan lainnya dibuat terpisah sesuai dengan konsep tri mandala. Tumpang salu dalam perumahan Bali Aga berfungsi sebagai tempat pemujaan yang ditempatkan di dalam ruangan. Dalam perkembangannya, tumpang salu menjadi sanggah kamulan atau mrajan ditempatkan di utama mandala atau di utara atau timur, atau timur laut dari 
tempat tinggal merupakan bukti unsur asli yang masih melandasi proses perkembangan budaya (Geria, 2002: 176-177).

Dalam konteks pelaksanaan Saṃskāra yang ada di Desa Pedawa pemujaan terhadap leluhur sangat penting posisinya terlebih-lebih upacara yang kaitanya dengan upacara kematian maka pemujaan kepada leluhur menjadi yang utama. Mereka beranggapan bahwa semua yang mereka warisi sekarang adalah warisan leluhur yang patut diteruskan oleh generasi penerusnya.

\section{Kesimpulan}

Berdasarkan analisis yang dilakukan dapat disimpulkan bahwa pelaksanaan Saṃskāra di Desa Pedewa masih menggunakan Sesapa sebagai bahasa pengantarnya. Pelaksanaan Saṃskāra di pimpin oleh Balian Desa yang memiliki tugas utama mengantarkan proses upacara yang dilaksanakan. siklus pelaksanaan Saṃskāra di Desa Pedawa terdiri dari (1) Kayeh di Cangkupe, (2) Kepus Pungsed (Kepus Puser), (3) Nampi, (4) Nanggapang Abulan Pitung Dina, (3) Tiga Bulanan, (4) Ngotonin, (5) Nyambutin, (6) Nyerimpen, (7) Pawiwahan, (8) Metatah, (9) Upacara Kematian dan (10) Ngangkid. Sedangkan bentuk sesapa yang digunakan oleh masyarakat Desa Bali Aga berupa Bahasa Bali Dialek Pedawa yang ditunjukan kepada Para Dewa, kepada para Leluhur, dan kepada Para Bhuta.

\section{Daftar Pustaka}

Edi, S. (2004). Bentuk dan Isi Mantra. Jurnal Humaniora Volume 16, No.3, Oktober $2004: 321-331$.

Geriya. I.W. (1991). Peranan Agama Hindu dalam Transformasi Budaya. Denpasar : Institut Hindu Dharma.

Hooykas, C. (1951). Penyedar Sastra. Jakarta: J.B.Wolters.

Koran Bali Express Jawa Post Group Terbitan 26 Maret 2021

Lanus. S. (2014). Puja Tri Sandhya: Indian Mantras Recomposed and Standardised in Bali. Oxford University Press and The Oxford Centre for Hindu Studies. USA.

Mayuko, H. (2015). Bentuk Hormat Dialek Bahasa Bali Aga dalam Konteks Agama. Jurnal Masyarakat Linguistik Indonesia ISSN : 0215-4846. Jakarta.

Moleong, L.J. (2013). Metodologi Penelitian Kualitatif. Bandung: PT Remaja Rosdakarya. 
Pudja, G. (2005). Bhagawad Gita (Pancama Veda). Surabaya: Paramita.

Sukrata, I.W. (1995). Tinjauan Upacara Ngangkid Sebagai Pelaksanaan Pitra Yadnya di Desa Adat Pedawa Kecamatan Banjar Kabupaten Buleleng. Singaraja : Sekolah Tinggi Keguruan Dan Ilmu Pendidikan.

Titib. I. M. (2003). Teologi dan Simbol-Simbol dalam Agama Hindu. Surabaya : Paramitha.

Informan : Nyoman Kalam (Pan Karpini) (Balian Desa) 